\title{
Auditory perception of dissonant polyrhythms
}

\author{
CECILE BEAUVILLAIN \\ Laboratoire de Psychologie Expérimentale, Université Renè Descartes et EPHE, Associè au CNRS \\ Paris, France
}

\begin{abstract}
Subjects synchronized their taps with each isochronous pulse train in a polyrhythmic superposition of two conflicting pulse trains (the 2 by 3 and the 3 by 4). Perception of each isochronous pulse train depends on the presentation rates. At fast presentation rates, each pulse train could be perceived as a separate stream, organized by the frequency similarity principle. At slow presentation rates, the perception of a pulse train interferes with the other pulse train; it depends on other factors such as interval duration, frequency, and position of the elements in the polyrhythmic structure. These data are consonant with the phenomenon of "steam segregation."
\end{abstract}

It is generally agreed in the psychological literature on rhythm perception that the auditory system integrates successive sounds into a perceptual pattern. Rhythm perception is characterized by the organization of successive discrete tones into a holistic pattern. Bolton (1894) was the first author to underlie this characteristic in his introspective work. A series of identical sounds, separated by equal intervals, is spontaneously perceived as groupings of two, three, or four elements. The groupings may be based on a single qualitative or quantitative difference introduced in a sequence of stimuli. It has been shown that pause, accent, or run of identical elements results in the organization of a sequence of tones into rhythmical groups (Fraisse, 1982; Preusser, Garner, \& Gottwald, 1970; Royer \& Garner, 1966). These authors agree that auditory perceptual patterns are built according to the temporal succession of sounds.

An alternative view is that the auditory system does not necessarily integrate all successive sounds but only those that arise from the same source. "In a complex environment with many simultaneous sounds, auditory perception seems to be affected by heuristic processes that try to 'parse' the acoustic input and recover the combination of acoustic components contributed by each separate source of sound" (Bregman, 1978, p. 63). The processes whereby the streams are constructed tend to follow the principles described by the Gestalt theory: similarity, proximity, simplicity, and good continuation, and each one can determine the formation of "auditory streaming." Thus, if a sequence of discrete tones is presented rapidly, it seems that the succession of different tones "splits" perceptually into two or more parallel sequences, each organized by the similarity principle. This phenomenon has been referred to as "stream segregation"; the splitting into two streams depends

The author's mailing address is: Laboratoire de psychologie Expérimentale, Associé au CNRS, Université de Paris V, 28 rue Serpente, 75006 Paris, France. on the frequency separation of the tones (Bregman \& Campbell, 1971; Miller \& Heise, 1950; Van Noorden, 1975).

This second approach is not in agreement with the theories of rhythm grouping that view the integration of successive sounds as the main principle of auditory perceptual organization. The difficulty with most studies on rhythm lies in the fact that they are based on the analysis of a single monorhythmic line. In a monorhythmic line, relations between elements are essentially established on the order of succession and no other organization competes with it, while in polyrhythmic lines, different organizations may be perceived. The study of the perception of complex rhythms might throw some light on our comprehension of the perception of musical sequences.

Within this perspective, syncopated auditory polyrhythms are particularly interesting. Syncopated polyrhythms, also called dissonant polyrhythms, are defined as the simultaneous superposition of two conflicting pulse trains in which the rates are not integral multiples of each other (for instance, the 2-by3, the 3-by-4, but not the 2-by-4) (Yeston, 1976). Each pulse train is isochronous, and there is a common point at which the elements of each pulse train coincide. The conflict between the two pulse trains results in syncopation. Thus, in the 2-by-3 polyrhythm, the tones of the 2-pulse train occur two times per pattern repetition, whereas the tones of the 3-pulse train occur three times per pattern repetition. In the same way, in the 3-by-4 polyrhythm, the tones of the 4pulse train occur four times per pattern repetition. If the tones of the 2-pulse trains differ in frequency, subjects may perceive a sequence of different elements organized by the law of proximity; in the 2by-3 polyrhythm, one will perceive a separate stimulus followed by three near stimuli (Figure 1a), whereas in the 3-by-4 polyrhythm, one will perceive a separate stimulus alternating with two near stimuli (Figure 2a). On the other hand, the subjects may organize the structure by integrating only the stimuli coming from 

1a) $\begin{array}{lllll}A & & & & \\ \square & & \square & \square & \square \\ B & B & \text { A } & \text { B }\end{array}$

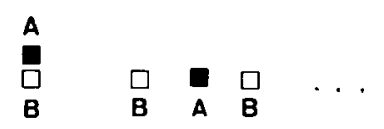
2a) $\begin{array}{llll}\text { A } & \text { A } & & \text { A } \\ \square & \square & \square & \square \\ \text { B } & \text { B } & \text { B } & \text { B }\end{array}$
$\begin{array}{lllll}\mathbf{A} & \text { A } & & \text { A } & \\ \mathbf{D} & & & & \\ \square & \square & \square & \square & \square \\ \text { B } & \text { B } & \text { B } & \text { B } & \end{array}$

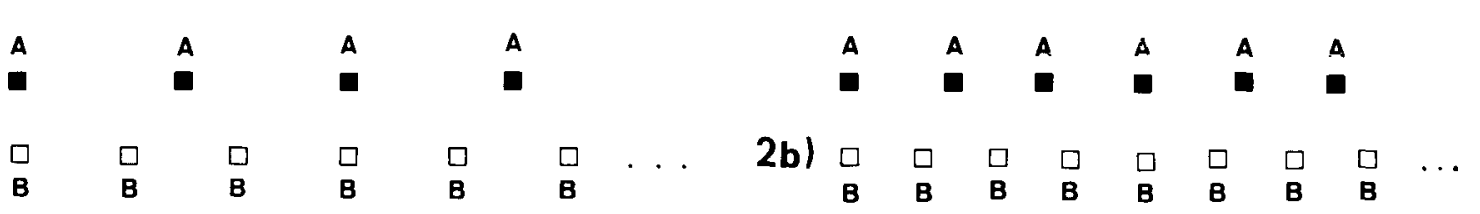

Figures 1-2. A schematic representation of the two alternating organizations in the 2-by-3 and the 3-by-4 polyrhythms. Proximity organization is represented in Figures $1 \mathrm{a}$ and $2 \mathrm{a}$ and frequency similarity organization is represented in Figures $1 \mathrm{~b}$ and $2 \mathrm{~b}$ for the 2 by-3 and 3-by-4 polyrhythm, respectively.

the same source. They may use the similarity of frequencies and, as a result, may perceive the stream composed by the AAA elements or the stream composed by the BBB elements (Figures $1 \mathrm{~b}-2 \mathrm{~b}$ ).

In their investigation of syncopated auditory polyrhythms, Handel and Oshinsky (1981) and Oshinsky and Handel (1978) asked their subjects to tap the beat (i.e., the meter) of polyrhythms presented at different repetition rates. Their results showed that different patterns of meter interpretation corresponded to different polyrhythms. For some polyrhythms, the meter interpretation was solely a function of temporal intervals between elements, while for others, it was based on several factors: presentation rate, element frequency, and pulse-train preferences. Since subjects were asked to tap along the perceived beat ("to keep time"), that is, to synchronize to the preferred elements of the polyrhythm, the results are ambiguous; furthermore, a great diversity in the interpretation of meter was observed.

In a preliminary work on the production of dissonant polyrhythms, the 2-by-3 and the 3-by-4, we investigated the mechanisms of regulation by a sequential analysis of musical performance, using musically trained subjects (Beauvillain, 1981). Subjects were asked to simultaneously produce the two pulse trains of a polyrhythm by tapping with their two hands. The results indicated that the regulatory mechanism was an absolute function of the tempo, that is, of the interval duration. It is only at interval durations within the range of $300-450 \mathrm{msec}$ that subjects are capable of producing equal temporal intervals in each pulse train, that is, a polyrhythmic organization characterized by the superposition of two rhythmic lines. At interval durations of about $600 \mathrm{msec}$, subjects controlled only the duration of interpulse intervals, as in a monorhythmic organization, by integrating the successive intervals produced by the two hands alternately. A sequential analysis of autocorrelations between the successive intervals corroborated the descriptive analysis, demonstrating that the statistical dependency between the different intervals changes with the tempo or the subjects' execution rate (Beauvillain \& Fraisse, 1984).

These results suggest that polyrhythmic organization is an absolute function of the tempo of execution. The superposition of two parallel and conflicting pulse trains seems to depend on the execution rate. Since this finding was obtained with a motorproduction task, it was necessary to confirm that it applied also to an auditory task, that is, that the perception of each pulse train of these polyrhythm depended on the presentation rate. The purpose of the present experiment was to study the perception of each pulse train of dissonant polyrhythms with different tempos of presentation, using musically naive subjects.

In the present study, dissonant polyrhythms, the 2-by-3 and 3-by-4, composed of two pulse trains with fixed frequencies and temporal interpulse intervals, were either integrated into the same stream, as in the case of a monorhythmic line, or segregated into separate streams. The two frequencies were held constant, one frequency for the elements of an A stream and another one for the elements of a B stream. The interpulse temporal relationship was held constant, but the presentation rates were varied systematically. The perceptual organization of these polyrhythms was inferred from the subjects' responses of synchronization. The subjects were asked to synchronize their tapping with each pulse train of the polyrhythm. Each pulse train was composed of low or high tones, depending on the condition. Synchronization with a sequence of isochronous pulses is an elementary task, and a number of authors have underlined the precision and regularity of responses (Fraisse, 1978; Kristofferson, 1976; Michon, 1967). If each pulse train can be perceived as a figure or a ground, we shall conclude that the two pulse trains are perceptually equivalent and organized by the similarity of 
frequency. In this case, the input is structured into simultaneous streams. If each pulse train, composed of elements of equal frequency, cannot be perceived as a figure, an analysis of tapping responses will reveal the nature of perceptual organization and the existence of only one stream organized according to the succession of elements. We study here the effect of the presentation rate on these alternative organizations.

\section{METHOD}

\section{Subjects}

Twelve students in psychology served as subjects. They had had no musical training, and they were all right-handed.

\section{Materials}

Two different polyrhythms were used: the 2-by-3 and the 3by -4 . Each polyrhythm consisted of two conflicting pulse trains. In the 2-by-3 polyrhythm, the tone representing the 2-pulse train occurred two times per pattern repetition, and the tones representing the 3-pulse train occurred three times per pattern repetition. In the 3-by-4 polyrhythm, the tones representing the 3-pulse train occurred three times per pattern repetition, and the tone representing the 4-pulse train occurred four times per pattern repetition. Each pulse train was isochronous, and there was a common point at which the elements of each pulse train coincided.

The tones of the two pulse trains were sinusoidal waves separated by a musical seventh such that, in half the instances, one pulse was $264 \mathrm{~Hz}$ (C 3) and the second pulse was $495 \mathrm{~Hz}$ (B 4); in the other half, the frequencies of the pulse train were reversed. The two frequencies were dissonant, and each tone was audible when presented simultaneously with the other one.

Within each pulse train, the duration of an individual element was $60 \mathrm{msec}$.

\section{Pattern Rate}

Three rates of presentation were used. In the 2-by-3 polyrhythm, the pattern repetition rates, from the beginning of one pattern to the beginning of the following one, were $900,1,350$, and 1,800 msec. In the 3-by-4 polyrhythm, the rates were $1,200,1,800$, and $2,400 \mathrm{msec}$. These rates were such that they allowed an easy motor synchronization on interval durations from 300 to $900 \mathrm{msec}$. The different conditions are presented in Figure 3.

\section{Experimental Task}

On each trial, a polyrhythm was presented for a sequence of 30 pattern repetitions. Subjects were asked to synchronize their taps with the low-frequency tones or with the high-frequency tones as soon as they could.

Before starting the experiment, the subjects were presented with a 1-by-2 consonant polyrhythm in which the tones of the 1-pulse train occurred one time per pattern repetition and the tones of the 2-pulse train occurred two times per pattern repetition; there was a common point at which the elements of each pulse train coincided. The two frequency conditions were used.

\section{Experimental Design}

There were two sessions separated by a 10 -min pause. The subjects were tested individually in all 24 conditions ( 2 polyrhythms $\times 3$ presentation rates $\times 2$ frequency conditions $\times 2$ types of pulse trains with which subjects synchronized their responses).

Each session was composed of the same 12 patterns ( 2 polyrhythms $\times 3$ presentation rates $\times 2$ frequency conditions); the two sessions differed only in the pulse train with which the subjects synchronized their responses, the slower or the faster of the same polyrhythmic pattern. The order of presentation rates was counterbalanced. At each presentation rate, the 3-by-4 followed
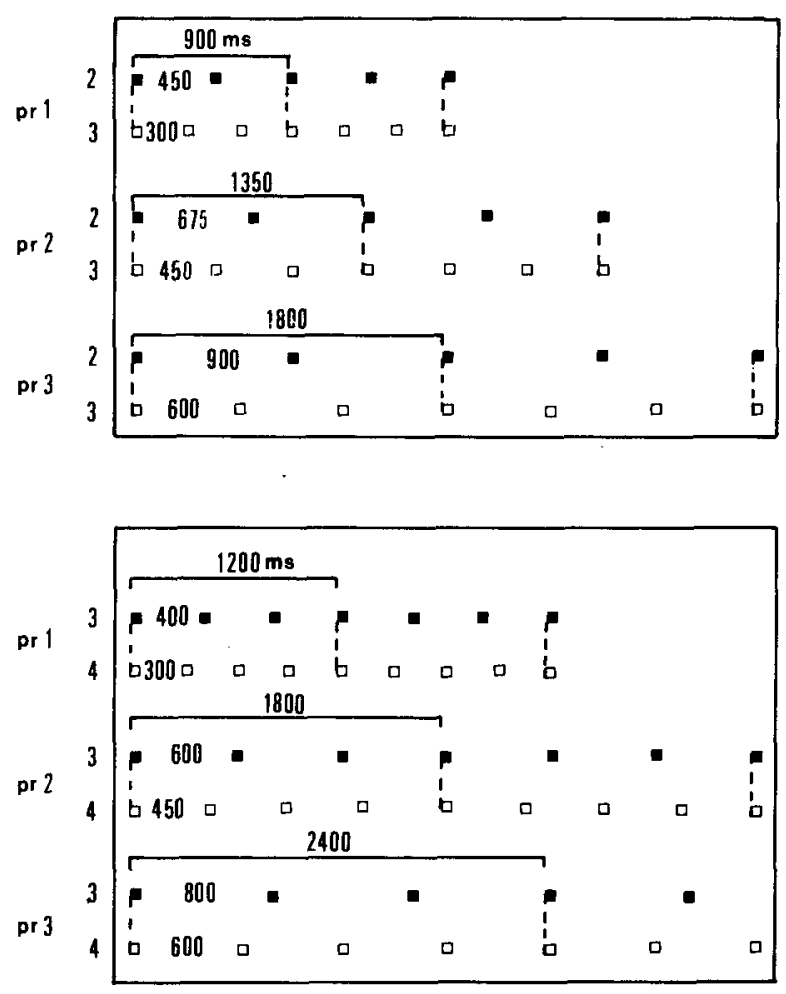

Figure 3. A schematic representation of the two polyrhythms, in each presentation rate. In the 2-by-3 polyrhythm, the interval durations of the 2-pulse train and 3-pulse train are 1/2 and 1/3 of pattern repetition time, respectively. In the 3-by-4 polyrhythm, the interval durations of the 3-pulse train and the 4-pulse train are $1 / 3$ and $1 / 4$ of pattern repetition time, respectively.

the 2-by-3, and the slower or the faster pulse train of the two polyrhythms had the same frequency. The frequency of the elements was changed on each trial; consequently, subjects synchronized with the slower pulse train in one trial and with the faster pulse train in the next.

\section{RESULTS}

Preliminary analysis indicated two main classes of responses: "omissions" (i.e., the number of taps is smaller than the number of stimuli in the synchronized pulse train) and "multiresponses" (i.e., the number of taps is higher than the number of the stimuli in the synchronized pulse train). "Omissions" before the beginning of tapping were not taken into account; three or four pattern repetitions generally preceded the beginning of the synchronization in the different conditions.

Although the percentage of "omissions" does not depend on the presentation rate and frequency (Table 1), "multiresponses" occurred when subjects synchronized with the slower of the two concurrent pulse trains, the 3-pulse train in the 3-by-4 and the 2-pulse train in the 2-by-3, mostly when they were composed of high-pitch elements. This effect is particularly important in the case of the 2-pulse train in the 2-by-3 


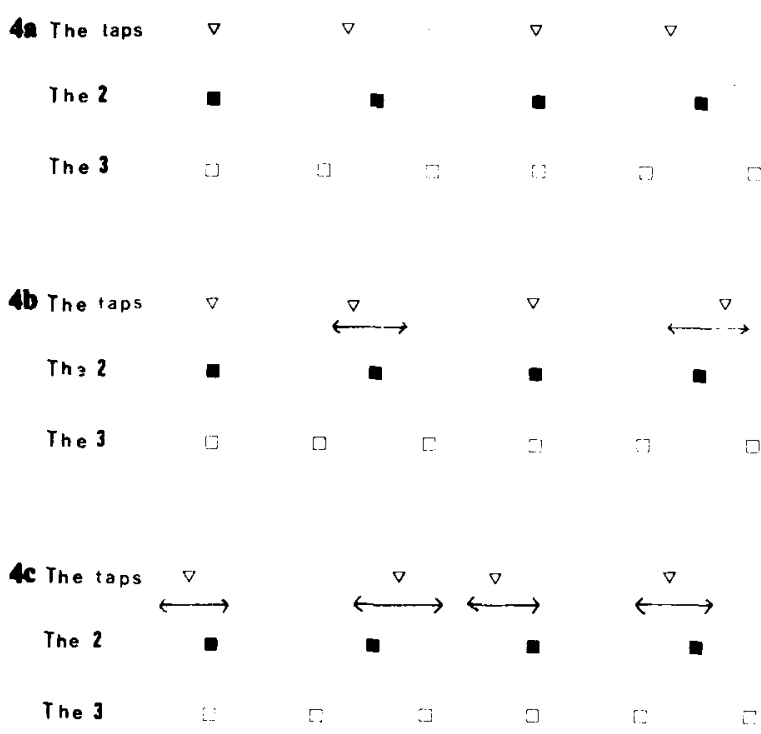

Figure 4. A schematic representation of three synchronization response patterns in the $2-b y-3$ polyrhythm. The arrows Indicate the positions of highly irregular synchronization responses.

polyrhythm. "Multiresponses" occurred primarily because subjects tapped for the first five or six pattern repetitions along with the two-pulse trains: many of these subjects tended to synchronize with some stimuli of the faster pulse trains in the subsequent pattern repetitions.

In a synchronization task, analysis in terms of the number of "omissions" and "multiresponses" is not sufficient to apprehend the response pattern, because subjects can produce random taps without synchronizing with the pulse train. To that end, two measures were used in the comparative analysis: the time lags between the taps and tones, and the standard deviations of time lags. The time lags between the taps and the tones may be anticipated or delayed, according to whether the taps anticipate (negative time lags) or follow (positive time lags) the tones. The time lags reflect the precision of the synchronization. The standard deviations of these time lags within trials reflect the regularity of synchronization. These two measures were done with data pooled over element position and with data over each element position in the polyrhythmic structure. The following comparative analysis used only the subjects who presented less than $7 \%$ of "omissions" or "multiresponses." Seven subjects in the 2-by-3 and eight in the 3-by-4 polyrhythm met this criterion. Although it could be argued that this arbitrary decision restricts the scope of the analysis, this procedure allows one to compare the different conditions using synchronization responses to only one of the two pulse trains.

\section{Time Lags of Synchronization in the 2-by-3 Polyrhythm}

Table 2 presents the mean time lags and standard deviations of time lags pooled over element position, according to the presentation rate and the pulse train (high or low) with which responses were synchronized. The phenomenon of anticipation previously observed in synchronization to a pulse train (Fraisse, 1978 ) in which the taps occur about $30 \mathrm{msec}$ before the sound (negative time lags) appeared here in most of the conditions, but some delayed responses appeared in some subjects in synchronizing with the 2-pulse train when it was composed of higher pitch elements at presentation rates 2 and 3 . Nevertheless, these mean deviations were not a relevant measure in a synchronization task, so we chose to base our analysis on the standard deviation of time lags.

An analysis of variance on standard deviations was performed $(7$ subjects $\times 3$ presentation rates $\times 2$ frequencies $\times 2$ pulse trains). There was a significant effect of presentation rate with the 2-pulse train $[F(1,6)=7.32, p<.05]$, whereas no effect appeared with the 3-pulse train. At the faster presentation rate 1 , the subjects synchronized their taps with the 2pulse train with the same regularity as they did with

Table 1

Means of Percentages of Omissions and Multiresponses for the Different Frequencies and Pattern Repetition (PR) Rate Conditions

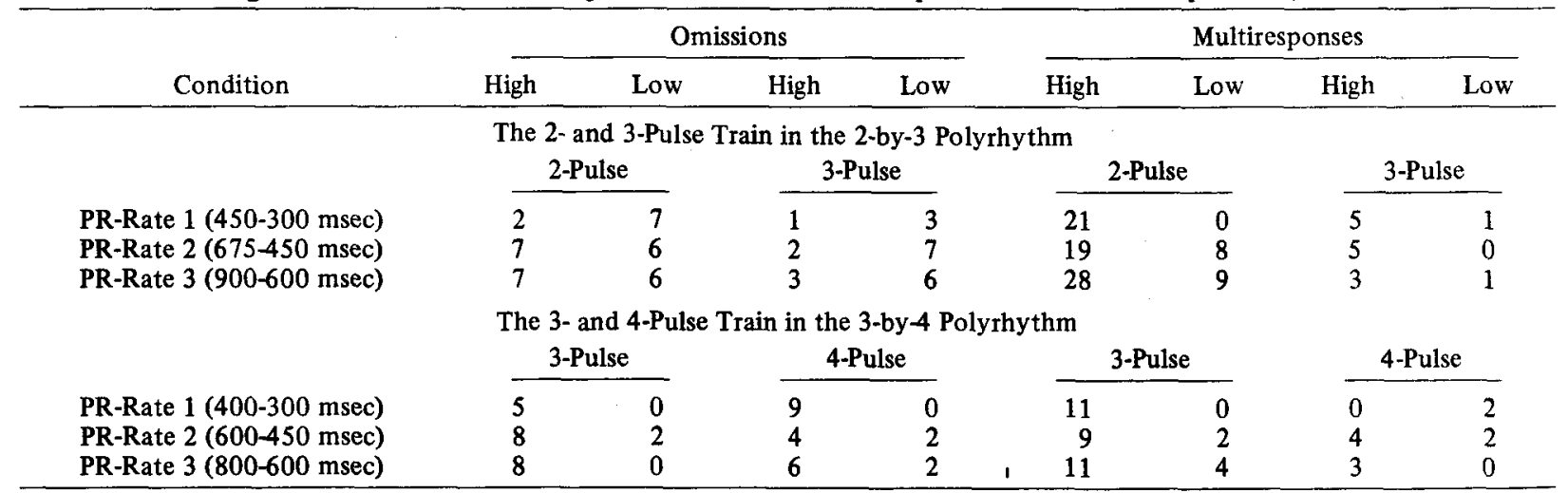

Note-Interval durations of the 2-and 3-pulse train for each pattern repetition rate are in parentheses. 
Table 2

Means and Standard Deviations of the 2-Pulse and 3-Pulse Train Time Lags (in Milliseconds) in the 2-by-3 Polyrhythm for the Different Frequencies and Pattern Repetition (PR) Rate Conditions

\begin{tabular}{|c|c|c|c|c|c|c|c|c|}
\hline \multirow[b]{2}{*}{ Condition } & \multicolumn{2}{|c|}{ High 2-Pulse } & \multicolumn{2}{|c|}{ Low 2-Pulse } & \multicolumn{2}{|c|}{ High 3-Pulse } & \multicolumn{2}{|c|}{ Low 3-Pulse } \\
\hline & Mean & SD & Mean & SD & Mean & SD & Mean & SD \\
\hline $\begin{array}{l}\text { PR-Rate } 1(450-300 \mathrm{msec}) \\
\text { PR-Rate } 2(675-450 \mathrm{msec}) \\
\text { PR-Rate } 3(900-600 \mathrm{msec})\end{array}$ & $\begin{array}{l}-21 \\
+12 \\
+8\end{array}$ & $\begin{array}{l}50 \\
93 \\
95\end{array}$ & $\begin{array}{l}-16 \\
-18 \\
-27\end{array}$ & $\begin{array}{l}39 \\
75 \\
79\end{array}$ & $\begin{array}{l}-38 \\
-57 \\
-48\end{array}$ & $\begin{array}{l}39 \\
31 \\
46\end{array}$ & $\begin{array}{l}-28 \\
-38 \\
-37\end{array}$ & $\begin{array}{l}28 \\
33 \\
33\end{array}$ \\
\hline
\end{tabular}

Note-+ sign indicates delayed responses and - sign anticipated responses. Interval durations of the 2-and 3-pulse train for each pattern repetition rate are in parentheses.

the 3-pulse train $[F(1,6)=1.2, p>.05]$, whereas at the intermediate presentation rate $2[F(1,6)=50.5$, $\mathrm{p}<.01)$, and at presentation rate $3[\mathrm{~F}(1,6)=9.17$, $\mathrm{p}<.02$ ], the subjects synchronized their taps with less regularity with the 2-pulse train. There was no significant effect of frequency of elements on the regularity of synchronization $[F(1,6)=3.72, p>.05]$.

An analysis of the regularity of synchronization over each element position in the polyrhythmic structure could indicate whether or not each pulse train was perceived as a succession of isochronous intervals independent of the position of its elements in the polyrhythmic structure. More precisely, synchronization with the 2-pulse train could be less regular, because (a) subjects synchronized irregularly with the two elements of the 2-pulse train, the regularity and the precision of time lags did not depend on the position of the elements in the polyrhythmic structure and, in this case, the 2-pulse was not perceived clearly (Figure 4c); (b) subjects synchronized irregularly with the second element, oscillating between responses of anticipation and delayed response (Figure $4 b$ ); or (c) responses to the second element were always responses of anticipation (or delayed responses), opposite to responses to the first element (Figure 4a). In the $a$ and $b$ patterns of Figure 4, precision and regularity of synchronization depend on the position of elements in the polyrhythmic structure.
Table 3 shows the mean time lags and standard deviations of each element of the two pulse trains. The three elements of the 3-pulse train are synchronized with the same precision and regularity at each presentation rate $[F(2,12)=1.58, p>.05]$. The two elements of the 2-pulse train are not synchronized with the same regularity: the second element is less regular than the first one at presentation rate $2[\mathrm{~F}(1,6)$ $=4.48, p<.10]$ and at presentation rate $3[\mathrm{~F}(1,6)$ $=15.7, \mathrm{p}<.01]$. Moreover, delayed responses occur for this second element, with an interval duration of about $70 \mathrm{msec}$ after the stimulus and yet below the auditory reaction time. On the other hand, the two elements of the 2-pulse train are synchronized with the same precision and regularity at the faster presentation rate 1 .

\section{Time Lags of Synchronization \\ in the 3-by-4 Polyrhythm}

Table 4 shows the means and standard deviations of time lags pooled over element position for each pulse train of the 3-by-4 polyrhythm in the different conditions. The phenomenon of anticipation of the taps (negative time lags), can be observed in all conditions; however, some delayed responses occurred when subjects synchronized with the 3-pulse train at presentation rates 2 and 3, especially when the 3pulse train was composed of high pitch elements.

Table 3

Means and Standard Deviations of Each Element Time Lags (in Milliseconds) for the Different Frequencies and Pattern Repetition (PR) Rate Conditions

\begin{tabular}{|c|c|c|c|c|c|c|c|c|c|c|c|c|}
\hline \multirow[b]{3}{*}{ Condition } & \multicolumn{4}{|c|}{ 1st Element } & \multicolumn{4}{|c|}{ 2nd Element } & \multicolumn{4}{|c|}{ 3rd Element } \\
\hline & \multicolumn{2}{|c|}{ High } & \multicolumn{2}{|c|}{ Low } & \multicolumn{2}{|c|}{ High } & \multicolumn{2}{|c|}{ Low } & \multicolumn{2}{|c|}{ High } & \multicolumn{2}{|c|}{ Low } \\
\hline & Mean & SD & Mean & SD & Mean & SD & Mean & SD & Mean & SD & Mean & SD \\
\hline \multicolumn{13}{|c|}{ The 3-Pulse Train in the 2-by-3 Polyrhythm } \\
\hline $\begin{array}{l}\text { PR-Rate } 1(300 \mathrm{msec}) \\
\text { PR-Rate } 2(450 \mathrm{msec}) \\
\text { PR-Rate } 3(600 \mathrm{msec})\end{array}$ & $\begin{array}{l}-38 \\
-62 \\
-61\end{array}$ & $\begin{array}{l}38 \\
27 \\
36\end{array}$ & $\begin{array}{l}-27 \\
-41 \\
-57\end{array}$ & $\begin{array}{l}27 \\
27 \\
25\end{array}$ & $\begin{array}{l}-43 \\
-50 \\
-32\end{array}$ & $\begin{array}{l}38 \\
30 \\
41\end{array}$ & $\begin{array}{l}-23 \\
-31 \\
-51\end{array}$ & $\begin{array}{l}28 \\
29 \\
34\end{array}$ & $\begin{array}{l}-39 \\
-60 \\
-56\end{array}$ & $\begin{array}{l}38 \\
31 \\
40\end{array}$ & $\begin{array}{l}-36 \\
-44 \\
-59\end{array}$ & $\begin{array}{l}25 \\
39 \\
36\end{array}$ \\
\hline \multicolumn{13}{|c|}{ The 2-Pulse Train in the 2-by-3 Polyrhythm } \\
\hline $\begin{array}{l}\text { PR-Rate } 1(450 \mathrm{msec}) \\
\text { PR-Rate } 2(675 \mathrm{msec}) \\
\text { PR-Rate } 3(900 \mathrm{msec})\end{array}$ & $\begin{array}{l}-24 \\
-26 \\
-41\end{array}$ & $\begin{array}{l}50 \\
40 \\
43\end{array}$ & $\begin{array}{l}-14 \\
-23 \\
-44\end{array}$ & $\begin{array}{l}38 \\
54 \\
50\end{array}$ & $\begin{array}{l}-19 \\
+47 \\
+20\end{array}$ & $\begin{array}{r}44 \\
105 \\
104\end{array}$ & $\begin{array}{l}-3 \\
-14 \\
-10\end{array}$ & $\begin{array}{l}40 \\
87 \\
85\end{array}$ & & & & \\
\hline
\end{tabular}

Note-+ sign indicates delayed responses and - sign anticipated responses. Interval durations of each pulse train for each pattern repetition rate are in parentheses. 
Table 4

Means and Standard Deviations of the 3-Pulse Train and the 4-Pulse Train Time Lags (in Milliseconds) in the 3-by-4 Polyrhythm for the Different Frequencies and Pattern Repetition (PR) Rate Conditions

\begin{tabular}{|c|c|c|c|c|c|c|c|c|}
\hline \multirow[b]{2}{*}{ Condition } & \multicolumn{2}{|c|}{ High 3-Pulse } & \multicolumn{2}{|c|}{ Low 3-Pulse } & \multicolumn{2}{|c|}{ High 4-Pulse } & \multicolumn{2}{|c|}{ Low 4-Pulse } \\
\hline & Mean & SD & Mean & SD & Mean & SD & Mean & SD \\
\hline $\begin{array}{l}\text { PR-Rate } 1(400-300 \mathrm{msec}) \\
\text { PR-Rate } 2(600-450 \mathrm{msec}) \\
\text { PR-Rate } 3(800-600 \mathrm{msec})\end{array}$ & $\begin{array}{l}-44 \\
-18 \\
-35\end{array}$ & $\begin{array}{r}48 \\
64 \\
116\end{array}$ & $\begin{array}{l}-46 \\
-44 \\
-10\end{array}$ & $\begin{array}{l}30 \\
67 \\
65\end{array}$ & $\begin{array}{l}-39 \\
-54 \\
-22\end{array}$ & $\begin{array}{l}52 \\
37 \\
73\end{array}$ & $\begin{array}{l}-47 \\
-39 \\
-24\end{array}$ & $\begin{array}{l}44 \\
43 \\
37\end{array}$ \\
\hline
\end{tabular}

Note-+ sign indicates delayed responses and - sign anticipated responses. Interval durations of the 3-and 4-pulse train for each pattern repetition rate is in parentheses.

Mean time lags, however, are not a relevant measure in a synchronization task; consequently, here again we analyzed the standard deviations of time lags that reflect synchronization regularity.

The analysis of variance of standard deviations $(8$ subjects $\times 3$ presentation rates $\times 2$ frequencies $\times 2$ pulse trains) yielded no significant effect of presentation rate for the 4-pulse train $[F(1,7)=0.39, p>.05]$; presentation rate for the 3-pulse train, however, was significant $[F(1,7)=24.7, p<.01]$. At the faster presentation rate 1 , subjects synchronized their taps with the same regularity with both pulse trains. At the intermediate presentation rate 2 , the difference was significant $[F(1,7)=5.16, p<.05]$. At the slower presentation rate 3 , the subjects synchronized their taps with less regularity with the 3 -pulse train $[F(1,7)$ $=6.63, \mathrm{p}<.05]$.

The effect of element frequency appeared on the slower presentation rate 3 , but this effect is significant only for the 3-pulse train, where the standard deviations are larger for high-pitch than for lowpitch elements $[F(1,7)=6.57, p<.05]$.

The means and standard deviations of time lags for any position in the polyrhythmic structure are shown in Table 5. The anticipation of the taps (negative responses) is observed for all elements of the 3- and 4-pulse trains and for all rates and frequency conditions. An analysis of variance of the standard devi- ations for each element of the 4-pulse train does not reveal any effect of element position in the polyrhythmic structure $[F(1,7)=1.37, p>.05]$. At presentation rate 3 , the first, third, and fourth elements seemed to be less regularly synchronized than the second one, particularly when composed of highpitch tones; but there was no significant difference $[F(1,7)=1.46, p>.05]$.

In most cases, some responses of anticipation are observed for the 3-pulse train; however, some subjects gave some delayed responses to the second and third elements at presentation rates 2 and 3, particularly for high-pitch tones. Furthermore, standard deviations for the second element are a little larger, but no significant effect is found $[F(1,7)=1.64$, $\mathrm{p}>.05]$.

\section{DISCUSSION}

The perception of isochronous pulse trains of the polyrhythmic structures, the 2-by-3 and the 3-by-4, depends on the presentation rate. At a fast presentation rate, subjects can perceive each pulse train as a figure element or as a ground element, according to the instructions of the experimenter directing them to one pulse train or another. The organizing "strength" of each pulse train is the same. At a fast presentation rate, subjects can discriminate each

Table 5

Means and Standard Deviations of Each Element Time Lags (in Milliseconds) for the Different Frequencies and Pattern Repetition (PR) Rate Conditions

\begin{tabular}{|c|c|c|c|c|c|c|c|c|c|c|c|c|c|c|c|c|}
\hline \multirow[b]{3}{*}{ Condition } & \multicolumn{4}{|c|}{ 1st Element } & \multicolumn{4}{|c|}{ 2nd Element } & \multicolumn{4}{|c|}{ 3rd Element } & \multicolumn{4}{|c|}{ 4th Element } \\
\hline & \multicolumn{2}{|c|}{ High } & \multicolumn{2}{|c|}{ Low } & \multicolumn{2}{|c|}{ High } & \multicolumn{2}{|c|}{ Low } & \multicolumn{2}{|c|}{ High } & \multicolumn{2}{|c|}{ Low } & \multicolumn{2}{|c|}{ High } & \multicolumn{2}{|c|}{ Low } \\
\hline & Mean & SD & Mean & SD & Mean & SD & Mean & SD & Mean & SD & Mean & SD & Mean & SD & Mean & SD \\
\hline \multicolumn{17}{|c|}{ The 4-Pulse Train in the 3-by-4 Polyrhythm } \\
\hline $\begin{array}{l}\text { PR-Rate } 1(300 \mathrm{msec}) \\
\text { PR-Rate } 2(450 \mathrm{msec}) \\
\text { PR-Rate } 3(600 \mathrm{msec})\end{array}$ & $\begin{array}{l}-39 \\
-58 \\
-46\end{array}$ & $\begin{array}{l}45 \\
38 \\
76\end{array}$ & $\begin{array}{l}-26 \\
-39 \\
-45\end{array}$ & $\begin{array}{l}45 \\
41 \\
35\end{array}$ & $\begin{array}{l}-20 \\
-53 \\
-39\end{array}$ & $\begin{array}{l}44 \\
35 \\
41\end{array}$ & $\begin{array}{l}-25 \\
-39 \\
-44\end{array}$ & $\begin{array}{l}46 \\
40 \\
35\end{array}$ & $\begin{array}{l}-15 \\
-48 \\
-31\end{array}$ & $\begin{array}{l}43 \\
37 \\
70\end{array}$ & $\begin{array}{l}-22 \\
-36 \\
-50\end{array}$ & $\begin{array}{l}41 \\
40 \\
33\end{array}$ & $\begin{array}{l}-17 \\
-56 \\
-41\end{array}$ & $\begin{array}{l}49 \\
32 \\
73\end{array}$ & $\begin{array}{l}-24 \\
-41 \\
-48\end{array}$ & $\begin{array}{l}47 \\
43 \\
33\end{array}$ \\
\hline \multicolumn{17}{|c|}{ The 3-Pulse Train in the 3-by-4 Polyrhythm } \\
\hline $\begin{array}{l}\text { PR-Rate } 1(400 \mathrm{msec}) \\
\text { PR-Rate } 2(600 \mathrm{msec}) \\
\text { PR-Rate } 3(800 \mathrm{msec})\end{array}$ & $\begin{array}{l}-41 \\
-29 \\
-48\end{array}$ & $\begin{array}{l}48 \\
51 \\
70\end{array}$ & $\begin{array}{l}-7 \\
-42 \\
-45\end{array}$ & $\begin{array}{l}28 \\
55 \\
52\end{array}$ & $\begin{array}{l}-38 \\
-12 \\
-21\end{array}$ & $\begin{array}{r}46 \\
69 \\
109\end{array}$ & $\begin{array}{l}-7 \\
-45 \\
-63\end{array}$ & $\begin{array}{l}32 \\
52 \\
61\end{array}$ & $\begin{array}{l}-53 \\
-14 \\
-38\end{array}$ & $\begin{array}{l}41 \\
53 \\
78\end{array}$ & $\begin{array}{l}-15 \\
-45 \\
-30\end{array}$ & $\begin{array}{l}30 \\
51 \\
47\end{array}$ & & & & \\
\hline
\end{tabular}

Note-+ sign indicates delayed responses and - sign anticipated responses. Interval durations of each pulse train for each pattern repetition rate is in parentheses. 
pulse train by using the information about frequency. The pulse train is perceived as a sequence of isochronous identical elements organized by the frequency similarity principle.

At slow presentation rates 2 and 3 for the 2-by-3 polyrhythm and 3 for the 3-by-4 polyrhythm, subjects' performance depends on another property of the polyrhythms: synchronization with the faster pulse train of the polyrhythms is easy, as if it were a sequence of isochronous identical elements, whereas synchronization with the slower pulse train is difficult, with subjects no longer perceiving the periodicity. Some subjects tend to synchronize their taps with some elements of the faster pulse train, and performance inferred from the variability of time lags of synchronization depends on other factors, such as interval duration, frequency, and position of the elements in the polyrhythmic structure.

The fact that, with the slower pulse train, the elements may be so separated in time that they cannot be organized might explain the performance observed at slow presentation rates. Our experimental results must be compared with other results on the effect of the interval duration on the standard deviation of responses in a synchronization task (Bartlett \& Bartlett, 1959; Woodrow, 1932). These experiments do not generally support the prediction of a linear increasing relation between interval duration and standard deviation. Bartlett and Bartlett (1959) found a standard deviation of $25-30 \mathrm{msec}$ for intervals in the range of $250-500 \mathrm{msec}$ and a standard deviation of $40 \mathrm{msec}$ for intervals of $900 \mathrm{msec}$. Woodrow (1932) demonstrated a standard deviation of $20-25 \mathrm{msec}$ for intervals in the range of $250-800 \mathrm{msec}$ Kristofferson (1976) confirmed this finding with trained subjects, obtaining a standard deviation of $15 \mathrm{msec}$ for intervals in the range of $250-550 \mathrm{msec}$ and one of $22 \mathrm{msec}$ for an interval of $800 \mathrm{msec}$. Standard deviations began to increase with durations in the range of $600-800 \mathrm{msec}$. Figure 5 illustrates our results when synchronized pulse trains were composed of high-pitch (Figure 4a) or low-pitch (Figure 4b) elements. We can see that the standard deviation of synchronization time lags increases more with interval duration than previously assumed. Moreover, with an interval duration of $600 \mathrm{msec}$, standard deviation depends upon the pulse train. For the two polyrhythms, we found a standard deviation about $65-93 \mathrm{msec}$ for the slower pulse train and one of 33-46 msec for the faster pulse train, except for the 3-by-4 polyrhythm, where the standard deviation was from 73 msec when the faster pulse train was composed of high-pitch elements.

Although the variability of synchronization depends on interval duration, the variability of the slower pulse train of the two polyrhythms cannot be explained by the interval duration alone. We suggest that interval duration must be equal to or less than

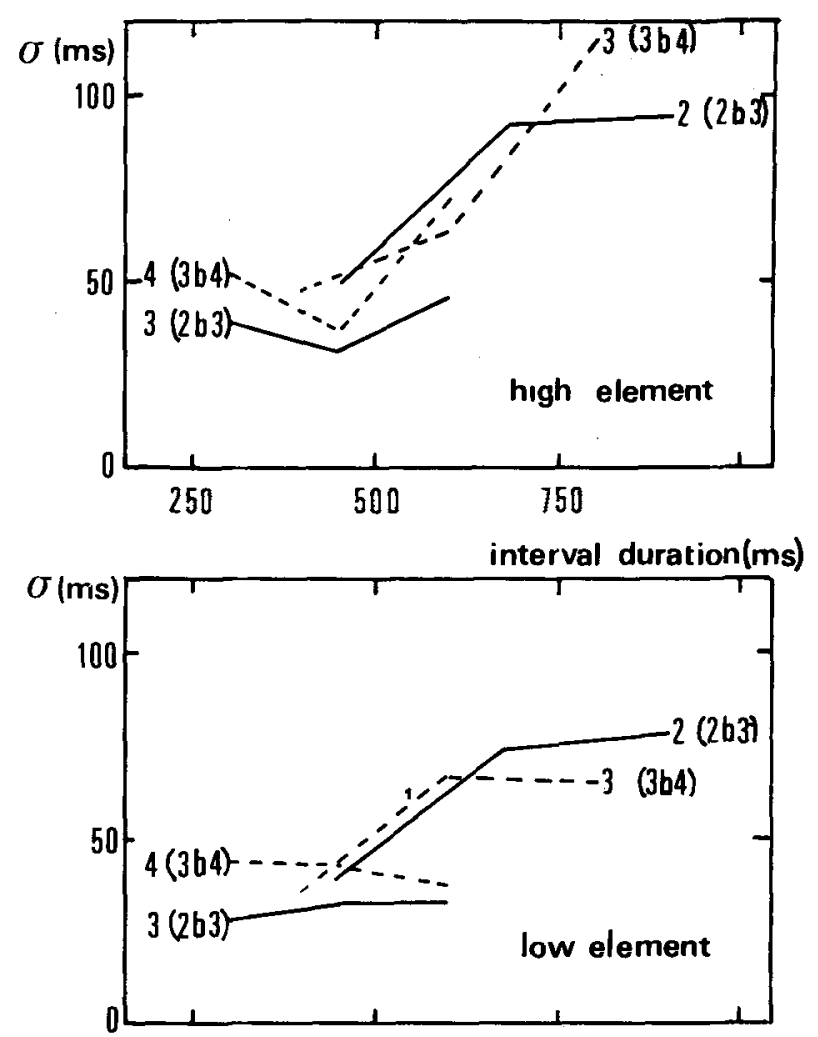

Figure 5. Standard deviations as a function of interval durations for each pulse train of the two polyrhythms according to the element frequency.

$500 \mathrm{msec}$ if each pulse train of the polyrhythm is to be perceived as an isochronous pulse train.

It is notable that performance was better with lowpitch elements when subjects synchronized with the slower pulse train, composed of interval durations equal to or greater than $600 \mathrm{msec}$. This result does not seem to be specific to the two pitches used in the present study. Handel and Oshinsky (1981) found better performance with low-pitch 2-pulse-train polyrhythms using frequencies of 440 and $586 \mathrm{~Hz}$ and with 3-pulsetrain polyrhythms (e.g., 3-by-4-by-5) using frequencies of 262,330 , and $392 \mathrm{~Hz}$. It is possible that the "click" of tones chopped on and off with short attack times was more audible for the low tones because the chop generated a transient that contained high-pitch energy. It should be pointed out that this frequency difference appeared in the ambiguous configurations only.

The observed effect of the position of the elements on the variability of synchronization responses suggests that, at slow presentation rates, subjects cannot perceive the slower pulse train as a figure element organized as a sequence of isochronous tones. At slow presentation rates, the better performance on the faster pulse train suggests that it becomes the salient component of the polyrhythmic structure on 
which is superimposed the other pulse train. The effect of the position of some elements of the slower pulse train seems to mean that the proximity of nontarget elements of the faster pulse train produces interferences with the perception of the slower pulse train. This can produce anticipated or delayed responses, or variable responses of synchronization.

To claim that the organization of temporal patterns composed of elements of different frequency depends on the presentation rate means that temporal patterns do not remain invariant across changes in presentation rates when the order of succession of elements is identical. If one can consider that rhythm is an ordering in temporal succession (Fraisse, 1978), this organization based on succession disappears with interval durations in a range of $150-300 \mathrm{msec}$ (for the interpulse interval durations). In this case, successive elements are perceived as separate. Frequency similarity is used, and each pulse train is perceived as a stream of identical elements without any interference of the other pulse train. These data are consonant with the phenomenon of "stream segregation," the splitting of a sequence of different tones depending on their separation in time and frequency.

\section{REFERENCES}

BARtLetT, N. R., \& BARTLETT, S. C. Synchronization of a motor response with an anticipated sensory event. Psychological Review, 1959, 66, 203-213.

Beauvillain, C. De l'organisation du successif à l'organisation du simultané dans la polyrythmie. Paris, thèse de 3ème cycle, 1981.

Beauvillain, C., \& Fratsee, P. On the temporal control of polyrhythmic performance. Music Perception, 1984, 1, No. 4.
Bolmon, T. L. Rhythm. American Journal of Psychology, 1894, 6, 145-238.

Bregman, A. S. The formation of auditory streams. In J. Requin (Ed.), Attention and performance (Vol. 7). New York: Halsted Press, 1978.

Bregman, A. S., \& Campbell, J. Primary auditory stream segregation and perception of order in rapid sequences of tones. Journal of Experimental Psychology, 1971, 89, 244-249.

Fraisse, P. Time and rhythm perception. In E. C. Carterette \& M. P. Friedman (Eds.), Handbook of perception (Vol. 8). New York: Academic Press, 1978.

Fraisse, P. Rhythm and tempo. In D. Deutsch (Ed.), Psychology of music. New York: Academic Press, 1982.

Handel, S., \& Oshinsky, J. S. The meter of syncopated auditory polyrhythms. Perception \& Psychophysics, 1981, 30, 1-9.

Kristofrerson, A. B. Low-variance stimulus-response latencies: Deterministic internal delays? Perception \& Psychophysics, 1976, 20, 89-100.

Michon, J. A. Timing in temporal tracking. Soesterberg, The Netherlands: Institute for Perception RVO-TNO, 1967.

MilleR, G. A., \& Heise, G. A. The trill threshold. Journal of Acoustical Society of America, 1950, 22, 637-638.

OshinskY, J. S., \& Handel, S. Syncopated auditory polyrhythms: Discontinuous reversal in meter interpretation. Journal of Acoustical Society of America, 1978, 63, 936-939.

Preusser, D., Garner, W. R., \& Gotwwald, R. L. Perceptual organization of two-element temporal patterns as a function of their component one-element patterns. American Journal of Psychology, 1970, 83, 151-170.

Royer, F. L., \& Garner, W. R. Response uncertainty and perceptual difficulty of auditory temporal patterns. Perception \& Psychophysics, 1966, 1, 41-47.

van Noorden, L. P. A. S. Temporal coherence in the perception of tone sequences. Thèse de Doctorat, Eindhoven, 1975.

Woonrow, $H$. The effect of rate of sequence upon the accuracy of synchronization. Journal of Experimental Psychology, 1932, 15, 357-379.

YESTON, M. The stratification of musical rhythm. New Haven, Conn: Yale University Press, 1976.

(Manuscript received October 18, 1982; revision accepted for publication July 29,1983 .) 